\title{
The Strategies in C-E Translation of Public Sign-Based on the Study of Public Sign Translation of Qingdao*
}

\author{
Dongmeng Liu \\ School of Foreign Languages, Qingdao University of Science and Technology, Qingdao, China
}

\begin{abstract}
On the basis of investigation carried out in Qingdao, the paper points out that there are a lot of mistranslations and errors in Chinese-English translation of public signs. In order to improve and standardize the public sign translation, the paper tries to classify translation errors, compare English and Chinese signs and propose some feasible translation strategies and suggestion for the C-E translation of public signs.
\end{abstract}

Index Terms - public signs, error analysis, translation strategies

\section{INTRODUCTION}

With China's fast economic development, especially with the host of the 2008 Olympic Games and the World Exp. in China, the study of bilingual public signs has become a very hot topic. There will be more and more international events held in China, more and more foreigners from all over the world coming to China to travel and do business. All these international practices and activities make the translation of public signs essential, while mistranslated signs may provide some real challenges for the organizers, spectators and tourists from various countries. Public signs in China play the role of more than a "name card" of a city but the international image of our country.

Review of Research on Public Sign Translation in China

Previous researches on the C-E translation of public signs largely focused on the micro-level of primary data-enumerating and specific error-correcting, but often failed to work out a feasible theoretical guidance on the macro level. Word-for-word translation is still a frequently employed strategy at present, leading to English signs of poor readability and acceptability.

Most essays only discuss the problem form a special perspective and give much consideration to individual cases. Therefore, there has not been a thorough and systematic study of the distribution of error frequency and the causes of these errors in C-E translation of public signs.

Functionalism, emerging in 1970s in Germany, has been mainly used as the guideline to analyze the existing problems in translating public signs in China recently. Skopostheorie, the core theory of functionalism, regards translation as an act of communication. Any act of communication contains an aim or purpose which leads to a certain result. It claims that the aim or purpose of translation is of utmost importance in the act of translation — "the end justifies the means" (Nord, 2001, P. 29). Functionalists believe that translation has come to be considered as the production of a specific text for certain people of the target language with a specific aim. Any method becomes valid if it fulfills the aim of translation or the intended function.

Luo Xuanmin (2009) said that functionalism has its own disadvantages while it does shed light on the translation of public signs. If we do not have a thorough, correct and detailed understanding about a theory, it is likely to be abused. Functionalism is one of those theories that have been abused, which would lead to the absence of professional ethics in public sign translation. Within the framework of Skopostheorie, the translators tend to adopt a liberal strategy in order to cater to the target audience's convenience. Anything difficult or culture-specific in the translation process tends to be omitted, deleted or replaced intentionally.

Skopostheorie is quite effective to solve some problems in translation practice when the intended function of target text is exactly the same as the function of source text. However, functional approaches overemphasize the function of translation. Furthermore, what Skopostheorie focuses on is not the function of the original, but the function the target text is to achieve. A good translation is one which performs the same or similar function in the target culture. Translation strategy depends on whether the translated TT can serve its expected purpose instead of whether it is maximally faithful and equivalent to the ST. The status of ST is greatly reduced from the "sacred original" to merely "information offered" while much more importance is attached to target receivers and target culture. Therefore, it destroys the ST and neglects the obscure and specific style of the original language and culture.

Thus, this paper, based on Skopostheorie, attempts a multi-perspective study, examines the current practice in C-E translation of public signs and tries to propose some feasible and practical strategies for translators, using real cases of

\footnotetext{
* This paper belongs to a research project of social science of Qingdao University of Science and Technology.
} 
Qingdao to illustrate.

\section{The InVESTigation of C-E Translation of Public Signs In Qingdao}

\section{A. Present State of Public Sign Translation in Qingdao}

C-E translation of public signs get improved after Qingdao became the host city for 2008 Olympic Games, since China began its campaign of correcting and standardizing translation of public signs throughout the country. However, the current situation of sign translation in Qingdao is still far from satisfactory, with so many mistakes existing in the English version of public signs.

\section{B. Classification of Errors of Public Sign Translation}

\section{Mistranslation on the Linguistic Level}

\subsection{Spelling Errors}

As the most common and easiest errors to be corrected, misspellings simply arise from carelessness or painting mistakes, which also comprise underuse or overuse of capitals, space etc..

E.g. 1 通往卫生间 Acess to Toilet (Access to Toilet)

E.g. 2 请沿站台过往 Please Pass along the Plat Form (Please Pass along the Platform)

\subsection{Diction Errors}

Diction errors, wrong choice of words, often cause confusing or misunderstanding of public signs. The reasons may be lacking of understanding the source text or the related background of the target culture or just misusing some words.

To avoid the mistakes in diction, a systematical checking mechanism should be brought in. We need to check whether the translation match the situation well in C-E translation of public signs.

E.g. 3 如遇火警, 请勿使用电梯。Don’t Use Lift When In Fire. (Do Not Use Elevator In Case Of Fire.)

E.g. 4 请给老、弱、病、残、㭆让座。Please Offer the Seats to the Old, Weak, Sick, Crippled and Pregnant. (Please Offer Your Seat for the Senior, the Weak, the Sick, the Disabled and Pregnant Woman.)

\subsection{Grammar Errors}

Traditionally grammar was analyzed in terms of morphology and syntax, with morphology dealing with word structure and syntax the structures larger than word. Therefore, grammatical errors in this paper include both morphology and syntax errors.

The grammatical mistakes usually arise out of translators' language incompetence, the sentence just being translated word by word without minding its grammatical and syntactical structure.

E.g. 5 我们承诺减少您的等待时间 Reduce Your Waiting Time by Every Second in Cashier Line Is Our Commitment. (Reducing Your Waiting Time by Every Second in Cashier Line Is Our Commitment.)

\section{E.g. 6 香烟售出 概不退换 Cigarettes Can Not Return After Selling (Cigarettes Are Nonreturnable)}

\section{Mistranslation on the Cultural Level}

\subsection{Word-for-word Translation}

This kind of errors often result from over-literal translation in which the translators rigidly adhere to the original form and content and the source text is just translated word by word at its face level. "Some translators simply cannot figure out the meaning of the original, and they resort to a word-for-word translation due to a mistaken notion that this is an easy way out." (Jin Di and Nida, 1984, P.1)

E.g. 7 谨防扒手! Be Careful with Thieves. (Beware of Pickpocket.)

E.g. 8 买一赠一 Buy One, Present One. (Buy One, Get One Free.)

\subsection{Poor Acceptability}

Poor acceptability occurs when the readers of the target text find it difficult to understand the translation, though it is grammatical correct and there is no spelling mistake. The translator fails to express the exact meaning of the source text, due to his wrong inference coming from his contextual information or his real-world encyclopedic knowledge of the schema for the text.

E.g. 9 软座 硬座 Soft Seat, Hard Seat (Firs-class Seat, Standard Seat)

E.g. 10 紧急制动 Emergency Braking (Emergency Use Only)

2.3 Harsh Tone (Command Rather Than Request):

Public signs bear the function of directing, but in English they usually present the information without any intention of compelling or restricting. Therefore, a proper translation should offer the content of the service rather than command the public to do so.

E.g. 11 必须穿救生衣 Must Wear Life Jacket (Please Wear Life Jacket)

E.g. 12 禁止球类运动 Ball Games Is Forbidden (No Ball Games Allowed)

\subsection{Informativeness}

Errors in Informativeness refer to the cases in which a text contains more or less information than is necessary, which leads to information redundancy or text inaccessibility.

To enhance the informativeness of the messages transferred from the source language to the target language, the 
translator should try his best to preserve the cultural messages, and the cultural background should also be conveyed, if necessary.

E.g. 13 安心购物, 正在摄像中。Be Recording (For Your Personal Safety and Security, CCTV is in Operation.)

\section{E.g. 14 严禁非本部门人员入内 No Entry Except This Department's Staff (Staff Only)}

\subsection{Eyeball-effect}

Eyeball-effect refers to errors producing different communicative effects. Sometimes public sign translation is like literary translation where there is no standard reference for translators to look up, especially for those signs in tourist attractions, which are often written literally. For instance, there is a sign in a botanical garden in Missouri of America, "Please Give Me a Chance to Grow", which is not the usual English sign "Keep off the Grass".

E.g. 15 小草有生命, 脚下请留情。Keep off the Grass. (Grass Grows in Silence. Please Leave It Alone.)

E.g. 16 爱晚亭 Aiwan Pavilion (Autumn-admiring Pavilion)

TABLE 1 .

\begin{tabular}{|l|l|l|l|}
\hline Subjects & Errors & Total & Percentage \\
\hline \multirow{3}{*}{$\begin{array}{l}\text { Linguistic Level } \\
\text { S4\% }\end{array}$} & Spelling & 12 & $8 \%$ \\
\cline { 2 - 4 } & Diction & 25 & $17 \%$ \\
\cline { 2 - 4 } & Grammar & 9 & $6 \%$ \\
\hline \multirow{3}{*}{\begin{tabular}{l} 
Culture Level \\
\cline { 2 - 4 }
\end{tabular}} & Word-for-word & 32 & $21 \%$ \\
\cline { 2 - 4 } & Harsh Tone & 10 & $2 \%$ \\
\cline { 2 - 4 } & Poor Acceptability & 18 & $12 \%$ \\
\cline { 2 - 4 } & Informativeness & 9 & $6 \%$ \\
\cline { 2 - 4 } & Eyeball-effect & 8 & $5 \%$ \\
\hline
\end{tabular}

150 items of public sign samples are collected randomly in the study, including road \& traffic signs, institution names, visiting signs, public slogans and shopping signs etc. in Qingdao. All the samples are chosen form sources of recent years so that the data analysis ensures the topicality of the study and the novelty of the problems. After the error analysis on the C-E translation of public signs, we can see that translators need to improve their English proficiency especially in diction on the linguistic level, and pay more attention to the problems of word-for-word translation and poor acceptability on the culture level.

From the perspective of diagnosis of errors, most of them are attributed to interlingual errors on the culture level, which are mainly caused by mother tongue interference. Therefore, suggestions should be put forward from the perspectives of cultural adjustment and aesthetic equivalence.

\section{Systematic Study of Public Signs}

\section{A. Definition of Public Signs}

Public signs is a phrase which is adopted from English to refer to the concept of 公示语 that is right under discussion in this paper. In Oxford English Dictionary (2000), sign refers to a characteristic device attached to or placed in front of an inn or shop, as a means of distinguishing it from others or directing attention to it; in later use commonly a board bearing a name or other inscriptions, with or without some ornament or picture.

Belonging to social phraseology, public signs cover a wide range including catering, shopping, traveling, recreation, accommodation, medical and financial service as well as educational institution. With a lot of social communicative functions, public signs are employed widely on all sorts of occasions, ranging from warnings, notices, instructions, road markers, traffic signs, travel signs, construction signs, outdoor advertisements and government slogans etc.

\section{B. The Comparative Study of English and Chinese Public Signs}

Nord points out that every language is influenced by its own history, background and humanity and in turn reflects itself. Therefore, differences do exist in structure, language background, thinking pattern and expressing way between different languages. Linguistic translation problems arise from structural differences in the vocabulary, syntax and suprasegmental features of the SL and TL (Nord, 2001).

\section{Word Order}

The thinking patterns in Chinese culture differ apparently from that of English one, so the centre of power in Chinese is also greatly different from that in English. In English, signs often emphasize the point at the beginning, whereas in Chinese, signs are quiet implicit with the focus placing at the end of a phrase.

E.g. 17 非指定区域严禁吸烟 No Smoking except in Designated Areas

E.g. 18 坐定后系好安全带 Fasten Seat Belt While Seated.

\section{Diction}

Differences can also be observed in diction practice. Verbs or verbal phrases are more frequently used in Chinese signs to fulfill functions like compelling, restricting and warning, while gerunds and noun phrases are very common in English. Besides, English signs have a preference of using kernel words or notional words with articles and auxiliary verbs omitted. 
E.g. 19 严禁穿行 No Trespassing

E.g. 20 不收手续费 No Commission Charge

3. Mood

English signs usually sound implicative and euphemistic, but in contrast Chinese signs are quite straightforward and sometimes even impolite, with a touch of authority. Instead of aiming at the prohibited audience, English signs try to display the allowable aspect while Chinese signs tend to leave no space for compromise and consultation.

E.g. 21 禁酒区 Alcohol Free Zone

E.g. 22 此处禁止停车 Please Do Not Park Here

4. Voice

Passive voice is generally employed in English signs; Chinese signs, on the contrary, are more of active voice. Therefore, translators of public sign should take the target reader's identification and acceptability into account.

E.g. 23 禁止携带犬类入内 Dogs Not Allowed

E.g. 24 戴好防护镜和安全帽 Safety Glasses and Hard Hats Required

\section{Aesthetic Conceptions}

Generally, simplicity, accurateness and clarity highlight the characteristics of English public signs, which read fluently and euphonically. However, Chinese public signs often stress rhyme and parallelism in order to convey aesthetic values and easy remembrance.

E.g. 25 一慢, 二看, 三通过。 Slow Down, Look Around and Cross.

E.g. 26 安全第一, 旅客至上, 舒适便捷, 优质服务。Security, Convenience and Satisfaction.

Example 24 is a piece of advertising message at a coach station. The function of advertisement is to stimulate passengers to buy tickets. If it is translated into "With safety first and customer above all in mind, our airlines maintain efficiency and high quality of all the service we provide", it may not produce the persuasive effect and may lead to failure of promoting the company's image.

There comes the need of conducting stylistic analysis. Only after a comprehensive analysis of the features of source text, we can better serve the expected purpose of target text. However, this kind of stylistic analysis should focus on its functional significance rather than on the formal features of texts in the sign translation. We should also achieve functional equivalence from the perspectives of cultural adjustment and aesthetic equivalence.

After the analysis of different properties of Chinese and English public signs, we argue that the communicative translation strategy is still suitable for the translation of public signs, as they share many similarities: the language styles are quite concise, conspicuous and convenient. Furthermore, the figures of speech are frequently adopted both in Chinese and English public sign, although a series of differences exist, as mentioned above.

\section{Translation Strategies of C-E Translation of Public Signs}

Public signs, as a crucial communication material, have exhibited increasing importance in the global communication. The function of the special text is strong, the style quite distinctive and the communicative purpose very clear. Hence, the translation strategies should be based not only on the text's function but also on its literary style.

\section{A. Translation Strategies for Universal Signs}

Readers from different cultures may vary to a greater or lesser degree, but different languages could be culturally equivalent when performing some similar functions in their respective cultures. When the function of the target text is exactly the same as that of the source text, it would be called an "equi-functional" translation, where the functional equivalence comes true perfectly, where the receivers ideally do not notice that they are actually reading a translation. Therefore, if the corresponding expressions of the target language can be consulted, translators should borrow it directly.

E.g. 27 请走旁门 Please Use Other Doors.

E.g. 28 如需帮助请按钮 Please Press for Assistance

In this case, the conventional English signs are used so that the translation seems familiar to the readers and acceptable in English culture. This approach is very realistic and practical in the sign translation. Properly translated signs, while not as funny, would be more helpful to target readers and improve their experience - possibly enough to convince them to make a response.

\section{B. Translation Strategies for Culture-similar Signs}

Functionalism claims that the translation approaches should be determined by the function or expected purpose of the target text. If translation is to keep the original function of the source text, translators should be adapted to the target culture, namely, make slight change based on the similar expression in the target language. Target language would guide translators to make flexible linguistic choices, especially when they render some culture-specific information. Their choices in language have to be based on the acceptability level of target readers.

E.g. 29 八荣八耻 Eight Do's and Eight Don'ts (do's and don'ts)

E.g. 30 保护环境人人有责 Working Together We Can Make a World of Difference (Working Together for a 
Cleaner Thames)

The translation of Example 30 mimes the well-known sign for environmental protection in London "Working Together for a Cleaner Thames", which is much better than a literal translation "Protect the Environment Is Everyone's Business".

Mistranslated signs can actually be a lot worse than no translation at all. As sign translation is aimed at intended readers, the translator should try to achieve a familiar tone to touch the target readers. Based on this approach, the translators facilitate building up a so-called "cultural comfort zone", in other words, to achieve similar context, to cater to the acceptability and aesthetic values of the target readers. Thus, if the similar expressions do exist in English signs, translators should adapt them without hesitation.

By the approach, the translation should achieve the persuasiveness of the sign, arouse the amiableness on the part of target readers and justify the translators' choice of language in a given situation.

\section{Translation Strategies for Signs with Chinese Characteristics}

The language expressions present diversity, triggered by the different thinking modes, social values as well as cultural backgrounds between Chinese and English. Some public signs have very unique Chinese characteristics that are difficult to translate properly when no established expressions can be borrowed and no similar expressions can be adapted from English signs. For example, the use of parallel phrases, clauses and sentences is one of the most prevailing ways in Chinese public sings. Therefore, translators should create the proper translations according to the style and purpose of the target text.

E.g. 31 青岛是我家, 清洁靠大家。Everything We Do, We Do It for a Beautiful Qingdao.

E.g. 32 弘扬主旋律, 提倡多样化。Promote Mainstream Values and Uphold Diversity.

As in Example 31, in English culture, the similar sign is not expressed as that in Chinese. In Chinese, comparing one's city to one's family is to stimulate one's prompt response to keep it clean. In addition, “我家” rhymes with “大家”. To keep the original formal beauty in Chinese, it is better to be rendered as "Everything We Do, We Do It for a Beautiful Qingdao" so as to form a rhyme and give an emphasis.

Some public signs contain things that are particular to Chinese culture and have no equivalents in English. Therefore, when doing the translation of signs with unique Chinese characteristics, translators should do more creative work to enhance the charm of the source language. By the strategy of foreignization, the translation maintains the original flavor as much as possible to keep the foreignness of the sign. One thing needs to be noted here: the difference between Chinglish and China English.

The term "Chinglish" is commonly applied to ungrammatical or nonsensical English in Chinese contexts, and may have pejorative or deprecating connotation (Wikipedia, 2012). It is quite different from China English, which is based on Standard English and acceptable in English communication. Some words describe the peculiarities of Chinese culture, which will make China known to the outside world. On the other hand, they are also a contribution to the English vocabulary and expressions.

The quality of a translation should be assessed by the response of the intended readers, and the criterion should be whether the target readers have a good understanding of the source text. We adopt this creative strategy in order to make the translated version really intelligible and acceptable to the target readers. By the approach, the translation should also be reader-centered and target-culture-oriented, namely, considering reader's acceptance of languages, expectations and aesthetic view.

\section{CONCLUSION}

This paper sums up the current conditions and normalization of the C-E translation of public signs in Qingdao, based on the results of on-the-spot investigation applied with functionalist theory, and points out that the translation of public signs is the adaptation to the mental, social and cultural contexts as well as the lexical, semantic and syntactic structures of English. The dynamic adaptation to both language and context will enhance the quality of the translation of public signs and achieve effective cross-cultural communication.

The translation of public signs is by no means easy though they may contain just a few words. Public sign, as a crucial means, exhibits increasing importance in the global communication. Thus, in the process of the culture exchange, a systematic study on public signs and their translation will, no doubt, contribute a lot to better understanding the outside world. On the other hand, the standardizing of the bilingual signs will also be a way for China to be internationalized and propagate our own culture. By writing this thesis, the author aims at drawing more attention in the translation of public signs and inspires more valuable researches in this field.

\section{REFERENCES}

[1] Wang Yinquan, Chen Xinren. (2004). Mistranslation in Chinese Public Sign Discourse and the Underlying Problems. Chinese Translators Journal, 2, 81-82.

[2] Jin Di, Eugene A. Nida. (1984). On Translation. Beijing: China translation and Publishing Corporation.

[3] Luo Xuanmin, Li Shiwang. (2006). Some Thoughts on Public Sign Translation. Chinese Translators Journal, 4, 66-67.

[4] Nord. Christiane. (2001). Translating as a Purposeful Activity: Functionalist Approaches Explained. Shanghai: Shanghai 
Foreign Language Education Press.

[5] Simpson John. (2000). Oxford English Dictionary. Oxford: Oxford University Press.

[6] Wales Jimmy. (2001). Wikipedia. Web Transcription Tool. http://en.wikipedia.org/wiki/Chinglish (accessed 2/2/2013).

Dongmeng Liu was born in Binzhou, China in 1977. She received her Master's degree in linguistics from Ocean University of China, in 2003.

She is currently an instructor in the School of Foreign Languages, Qingdao University of Science and Technology, Qingdao, China. Her research interests include the theory and practice of translation.

Ms Liu is a member of China Association for Comparative Studies of English and Chinese. 